abscess, besides causing morbidity, may impair the functioning of the pelvic floor.

The importance of temperament when selecting patients is well shown by case 4 . Although the operation was technically uncomplicated and the patient obtained satisfactory function (after initial difficulties), he was unable to cannulate the pouch for psychological reasons. In retrospect probably he was unsuited to the procedure from the start; however, such an assessment is difficult to make preoperatively.

It must be emphasised that the colonic and rectal mucosa, which in ulcerative colitis is alone the site of the disease, is totally eliminated by this operation, the risk of further inflammation and of malignant change thus being removed. Therapeutically, therefore, it is as effective as proctocolectomy. Moreover, there has been no indication that operative risk and complications will be greater than in any other major pelvic operation. The severity of the disease in the rectum is of no great importance; the procedure may be carried out in the presence of ulceration, stenosis, or even a rectovaginal fistula. An adequate anal sphincter mechanism is, however, necessary.

Provided these initial results are maintained and reproducible this operation may offer a satisfactory alternative to proctocolectomy with a permanent ileostomy. Even at this early stage it seems desirable for it to be known that preservation of anal function is feasible. The plea is therefore made that the rectum be retained when operating for colitis so that the patient may be given a chance, should he wish it, to lose his ileostomy. It would, however, be wise in the first instance to confine this procedure to those who have an active antipathy to an ileostomy. They will be prepared to pay the price of any initial difficulties that may occur in order to avoid a stoma.

Requests for reprints should be addressed to: Sir Alan Parks, St Mark's Hospital, City Road, London EC1V 2PS.

\section{Addendum}

Two of the patients awaiting closure of the ileostomy have now had the operation. The early results are good. A patient with familial polyposis and carcinoma of the upper rectum has also been treated with an excellent functional result. In this case the indication was again total refusal to accept a permanent ileostomy.

\section{References}

${ }^{1}$ Goligher, J C, and Lintott, D, British fournal of Surgery, 1975, 62, 893.

${ }^{2}$ Beahrs, O H, Diseases of the Colon and Rectum, 1976, 19, 192.

${ }^{3}$ Kock, N G, Diseases of the Colon and Rectum, 1976, 19, 200.

${ }^{4}$ Jones, P F, Munro, A, and Ewen, S W B, British Fournal of Surgery, 1977 64, 615 .

5 Aylett, S, Archives Françaises des Maladies del'Appareil Digestif, 1974, 63, 585.

${ }^{6}$ Adson, M D, Cooperman, A M, and Farrow, G M, Archives of Surgery, $1972,104,424$

' Grüner, O P N, et al, Scandinavian fournal of Gastroenterology, 1975, 10, 641.

${ }^{8}$ Valiente, M A, and Bacon, H E, American fournal of Surgery, 1955, 90, 742.

${ }^{9}$ Oppolzer, R, Diseases of the Colon and Rectum, 1964, 7, 537.

${ }^{10}$ Hampton, J M, Diseases of the Colon and Rectum, 1976, 19, 133.

${ }^{11}$ Kock, N G, Archives of Surgery, 1969, 99, 223.

12 Parks, A G, in Clinical Surgery-Abdomen, Rectum and Anus, ed C Rob, $\mathrm{R}$ Smith, and C N Morgan, p 545. London, Butterworths, 1966.

13 Jeffery, P J, Hawley, P R, and Parks, A G, British fournal of Surgery, 1976, 63, 678 .

${ }^{14}$ Parks, A G, Proceedings of the Royal Society of Medicine, 1972, 65, 47.

15 Ravitch, M M, Surgery, 1948, 24, 170.

${ }_{16}$ Devine, A, Surgery, Gynecology and Obstetrics, 1951, 92, 437.

17 Best, R R, fournal of the American Medical Association, 1952, 150, 637.

${ }^{18}$ Drobni, A, Diseases of the Colon and Rectum, 1964, 7, 416.

(Accepted 28 April 1978)

\title{
Comparison between subjective and ultrasound assessments of fetal movement
}

\author{
A GETTINGER, A B ROBERTS, S CAMPBELL
}

British Medical fournal, 1978, 2, 88-90

\section{Summary and conclusions}

Forty pregnant women participated in a study to compare subjective with ultrasound assessments of fetal movements. A real-time ultrasound scanner was used. Movements were recorded for 45 minutes in all cases. There was a significant positive correlation between the number of movements recorded by the two methods, but the $95 \%$ confidence limits were wide and no correlation was found in those patients who recorded fewer than 20 movements in the study period. Thus "false-positive" information may be obtained from purely subjective data, and in patients reporting low "kick counts" fetal activity should be assessed from real-time ultrasound recordings.

\footnotetext{
Department of Obstetrics and Gynaecology, King's College Hospital Medical School, London SE5 8RX

A GETTINGER, BSC, research assistant (now medical student, Dartmouth Medical School, Hanover, New Hampshire, USA)

A B ROBERTS, MB, MRCOG, Rank research fellow

$S$ CAMPBELL, MB, FRCOG, professor
}

\section{Introduction}

The mother's assessment of fetal movement is used to indicate fetal wellbeing. ${ }^{1-5}$ Pearson and Weaver ${ }^{2}$ and Sadovsky et $a l^{10}$ equated low counts of fetal movement with poor fetal outcome, and most workers now accept that there is a good correlation between the true amount of fetal movement and the "kick counts" noted by the mother. ${ }^{6}$ Sadovsky et al used an electromagnetic measuring device and reported that on average patients felt $87 \%$ of the observed movements. We have carried out a study of subjective and objective assessments of fetal movement using a good-resolution real-time ultrasound scanner. We report here the results.

\section{Patients and methods}

Forty pregnant women between 25 and 40 weeks' gestation agreed to participate in the study. Thirty were clinically normal, five had raised blood pressure, three had growth-retarded fetuses as determined by serial ultrasound measurement of the circumferences of the head and abdomen, ${ }^{7}$ and two complained of diminished fetal movement. Ultrasound examination using an ADR real-time scanner (Tempe, Arizona) was performed with the patient semi-recumbent. The transducer was positioned to include a transverse section of the fetal trunk and both legs and held in place with a Kretz Technic clamp. In this way we observed most of the fetal movements, though 
probably some isolated arm and slight head movements escaped detection. Transmitted pulsations from maternal aorta and maternal and fetal respiratory movements were not recorded.

The patients decided for themselves what constituted fetal movement and recorded both the start and the end of each movement using a hand-held digital recorder attached to an electronic computer tape-punch. They familiarised themselves with the punch before the study began, and most of them had no difficulty, though in two cases the study had to be restarted because the women had not fully understood the instructions. The ultrasound image was simultaneously videotaped, and each session lasted 45 minutes, which we thought was the maximum time for the patient's comfort and co-operation. The television monitor was constantly viewed by the observer, who repositioned the transducer when necessary; but the patient could not see the screen. The start of the video recording was carefully synchronised with that of the patient's observation period. The videotapes were coded and analysed later by one observer, the beginning and end of each movement being punched. The tapes were then analysed by computer (PDP model $8 \mathrm{E}$ ) and measurements made of: (1) the total number of fetal movements; (2) the number of fetal movements recorded synchronously by ultrasound and by the patient (synchronous movements were defined as those in which there was either a time overlap between ultrasound and maternal recordings or an interval of two seconds or less between recordings); and (3) the percentage incidence of fetal movement, which was the total time for which the fetus was seen to move during any observation period expressed as a percentage.

Such elaborate analysis was necessary because studies of the reproducibility of the ultrasound method had shown that assessments of the number of fetal movements were subject to observer variation. In a study of 10 half-hour videotapes analysed "blind" by three separate observers and five analysed three times by the same observer at intervals of over one week we found that the best reproducibility was obtained from the percentage incidence of fetal movement, the mean SD being $1.98^{\circ}$, between separate observers and $1.25^{\circ} \circ$ between the same observer. When numbers of movements were studied the mean SD was 5.03 movements between separate observers and 3.04 between the same observer. This was because one observer viewing a continuous series of fetal movements might record it as one movement while another-perhaps even the same one on a different occasion-might record it as several. In view of the improved reproducibility in the results obtained by one observer we decided that one of us (AG) would analyse all the tapes. By analysing synchronous movements we could distinguish individual movements recorded by ultrasound and assess whether the patient had felt them. With these methods and by analysing the percentage incidence of fetal movement we avoided most of the bias or inaccuracy introduced by ultrasound recording.

\section{Results}

Number of movements-Over the 45 minutes a mean of $60 \pm \mathrm{SD}$ 35 movements was recorded by ultrasound, while the patients recorded a mean of $31 \pm 27$. There was a highly significant correlation between the two methods of assessment $(\mathrm{r}=0.739 ; \mathrm{P}<0.001)$, but the $95^{\circ} \%$ confidence limits were wide, indicating large individual variations. There was no significant correlation, however, between subjective and ultrasound assessments in the 16 women who recorded fewer than 20 movements $(r=0.080 ; P>0.7)$, while in the 24 women who recorded 20 or more movements there was a highly significant positive correlation $(\mathrm{r}=0.650 ; \mathrm{P}<0.001)$.

Synchronous movements-The patients recorded a mean of $26 \pm 26$ of the movements detected by ultrasound, and there was a significant correlation between the number of synchronous movements and the total number of ultrasound movements $(\mathrm{r}=0.784 ; \mathrm{P}<0.001)$ (fig 1 ). The $95^{\circ}$, confidence limits were again wide, and in the 19 women who recorded fewer than 20 of the movements detected with ultrasound there was no significant correlation between the two assessment methods $(r=0.223, P>0.3$; fig 2$)$; while in the 21 women who recorded 20 or more movements there was a significant positive correlation $(r=0.721 ; \mathrm{P}<0.001)$. Patients felt a mean of $40 \%$ of the movements recorded by ultrasound (range $0-94 \%$ ). Three women felt no movements at all, although ultrasound detected 19, 39, and 44 movements respectively.

Percentage incidence of fetal movement-The mean incidence of fetal movement recorded by ultrasound was $19 \pm 9 \%$, while that recorded by the patients was $8 \pm 11 \%$. There was a weak correlation between the two assessments $(r=0.435 ; P<0.01)$ but the $95 \%$

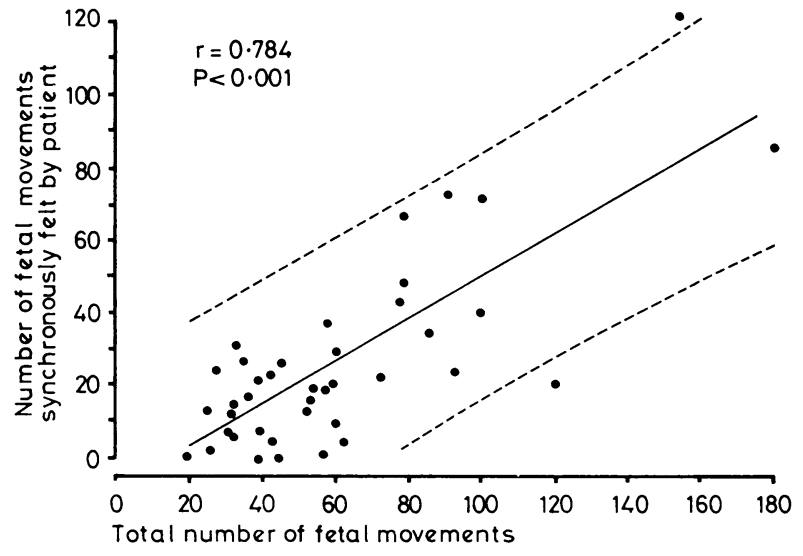

FIG 1-Relation between total number of fetal movements recorded by ultrasound and number synchronously felt by each patient. Dotted lines indicate $95 \%$ confidence limits.

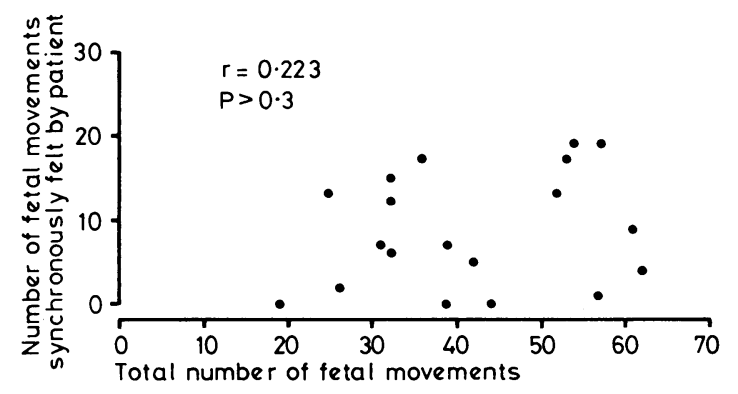

FIG 2-Relation between total number of fetal movements recorded by ultrasound and number synchronously felt by women who recorded fewer than 20 of the ultrasound movements.

confidence limits were again wide, and in those women who recorded an incidence of fetal movement of below $10 \%$ there was no correlation $(\mathrm{r}=0.190 ; \mathrm{P}>0.3)$.

There was a significant inverse correlation between both the number $(r=0.466 ; P<0.005)$ and the percentage incidence $(r=$ $0.512 ; \mathrm{P}<0.002)$ of fetal movements recorded by ultrasound and gestational age. The mother's appreciation of movement was not influenced significantly by her weight $(P>0.2)$, parity $(P>0 \cdot 1)$, or gestational age $(\mathbf{P}>0 \cdot 2)$.

\section{Discussion}

The reports by Pearson and Weaver ${ }^{2}$ and Sadovsky et al ${ }^{16}$ relating fetal movements to fetal wellbeing prompted an increase in the use of simple maternal counts of fetal movements for assessing the fetus. We were concerned that any test that relied so heavily on subjective assessment might give misleading information, and we therefore compared the most accurate and objective method of assessing fetal movement-namely, real-time ultrasound-with maternal assessment. The ultrasound method used. was not perfect, and studies of reproducibility showed that there was observer variation in recording the number of fetal movements because one long movement might be recorded as two, three, four, or even more shorter movements. To overcome this we analysed synchronous movements and the percentage incidence of fetal movement, which was the measurement with the best reproducibility. We thus consider that despite the difficulties inherent in the ultrasound method we assessed fetal movement objectively.

Owing to the size of the transducer the whole fetus cannot be viewed at once, so it is difficult to be sure that all fetal movement has been detected and recorded with the ultrasound method. We believe, however, that substantial movements of the head, arms, and legs are accompanied by movements of the 
fetal trunk, though small movements of the extremities are probably not recorded. Interestingly, only three patients recorded more movements than were detected by ultrasound, and in most cases ultrasound detected considerably more movements than did the patient.

Overall there was a significant correlation between movements observed using ultrasound and those recorded by the patient; but the confidence limits were wide, and a poor correlation was found in those women who felt the fewest movements. This is clinically important, as these are the patients who would become anxious about the wellbeing of the fetus. There was a good correlation, however, between subjective and ultrasound assessments in women who recorded 20 or more movements during the observation period.

Thus apparently many women have a reduced sensitivity to fetal movement and when low counts of fetal movement are reported a more objective method is needed to assess fetal activity. Pearson and Weaver and Sadovsky et al pointed out that it is not necessarily the number of movements that is the most important factor but rather the change in the number of movements, and we are carrying out longitudinal studies to see whether most women have a relatively constant sensitivity to fetal movement. We have also noticed, when watching fetal movement on the real-time display, that there are wide differences in the rapidity, degree, and vigour of the movements, which may also be relevant. Our policy is to admit to hospital women who complain of diminished fetal activity and to assess movement with the real-time scanner, monitoring fetal respiratory activity at the same time. By this means we hope to estimate fetal wellbeing more accurately, thus avoiding the "false-positive" information that may result from purely subjective measurements.

We thank Tony Roberts and Derek Cooper for help with the planning of the study, computing, and statistical analysis.

\section{References}

${ }^{1}$ Sadovsky, E, and Yaffe, H, Obstetrics and Gynecology, 1973, 41, 845.

2 Pearson, J F, and Weaver, J B, British Medical fournal, 1976, 1, 1305.

${ }^{3}$ Hems, D A, Biology of the Neonate, 1973, 23, 223.

4 Wood, C, Walters, W A W, and Trigg, P, British fournal of Obstetrics and Gynaecology, 1977, 84, 561.

5 Timor-Tritsch, I, American fournal of Obstetrics and Gynecology, 1976, 126, 70.

${ }^{6}$ Sadovsky, E, Polishuk, W Z, and Mahler, Y, Lancet, 1973, 1, 1141.

7 Campbell, S, and Thoms, A, British fournal of Obstetrics and Gynaecology, 1977, 84, 165.

(Accepted 28 April 1978)

\section{SHORT REPORTS}

\section{Radiotherapy for painful heel syndrome}

Many patients attend rheumatology or orthopaedic departments complaining of pain and tenderness on the plantar aspect of the calcaneum, or in the tendo calcaneus at or near its insertion. This may be a single complaint or may be associated with a general joint disorder. Currey ${ }^{1}$ suggests that it is due to a local inflammatory reaction. The symptom may subside spontaneously, but often persists. Treatment is usually a local injection of a corticosteroid drug, application of heat or ultrasound, excision of a plantar spur if present, or tenotomy. If all these methods fail, then $x$-ray treatment may be considered. The published work on radiotherapy for this condition has been reviewed by Dewing. ${ }^{2}$

\section{Patients, methods, and results}

Between March 1972 and November 1977 seventeen patients with painful heel (table) in whom other measures had failed were referred; nine had bilateral symptoms. Thirteen had plantar calcaneal pain, three had pain in the tendo calcaneus, while one had pain in the region of the right plantar calcaneum and left tendo calcaneus. Two patients were female. Ages ranged from 19 to 70 years.

All were treated to a dose of 1000 rads in five fractions given two or three times a week, by using large (eg $15 \times 15 \mathrm{~cm}$ ) parallel opposed lateral fields centred on the painful area with scattering material to make up for missing tissue. In most cases orthovoltage $(240-300 \mathrm{kV}) x$-rays were used, but five patients were treated by telecobalt. When both heels were treated at the same time the feet were held together and the beams included both feet. The dose was calculated at the midplane in each case. Eleven patients showed improvement, nine having complete and two partial relief. In eight improvement was immediate - that is, by the end of the course of treatment-and three others improved after two weeks, two months, and three months. Follow-up ranged from two to 43 months; two patients were lost.

\section{Comment}

Low-dose radiotherapy appears to relieve the painful heel syndrome in a high proportion of patients in whom other measures have failed. No skin or systemic reaction to radiation occurred in our patients but the risk of possible genetic damage or induction of malignancy must be considered. In one patient, a man aged 21 , the radiation dose to the scrotum was measured and totalled $2 \cdot 25$ rads during the whole course. Alexander ${ }^{3}$ estimated that the dose required to double the

Clinical details of 17 patients with painful heel who received radiotherapy

\begin{tabular}{|c|c|c|c|c|c|c|c|c|c|}
\hline \multirow{2}{*}{$\begin{array}{l}\text { Case } \\
\text { No }\end{array}$} & \multirow{2}{*}{ Sex } & \multirow{2}{*}{$\begin{array}{c}\text { Age } \\
(\mathrm{yrs})\end{array}$} & \multicolumn{2}{|c|}{ Site of pain } & \multicolumn{2}{|c|}{ Response } & \multirow{2}{*}{$\begin{array}{l}\text { Time for } \\
\text { response }\end{array}$} & \multirow{2}{*}{$\begin{array}{l}\text { Follow-up } \\
\text { (months) }\end{array}$} & \multirow{2}{*}{ Remarks } \\
\hline & & & $\mathrm{R}$ heel & L heel & $\mathrm{R}$ heel & L heel & & & \\
\hline 1 & $\mathbf{M}$ & 20 & - & Calcaneum & - & Complete & Immediate & 24 & Old Still's disease \\
\hline 2 & $M$ & 34 & Calcaneum & , & Complete & " & , & 43 & Ankylosing spondylitis and Crohn's disease \\
\hline 3 & $\mathbf{M}$ & 30 & Calcaneum & " & $\overline{\text { Partial }}$ & 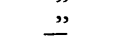 & 2 weeks & 4 & Later ankle pain \\
\hline $\begin{array}{l}4 \\
5\end{array}$ & $M$ & $\begin{array}{l}24 \\
55\end{array}$ & Calcaneum & Calcaneum & Partial & Complete & 2 weeks & Lost & "Gout \\
\hline 6 & $\mathrm{M}$ & 49 & Calcaneum & ” & None & None & Miminedrate & 24 & "Eye trouble" \\
\hline 7 & $\mathrm{~F}$ & 70 & ", & ”, & None & None & & 2 & \\
\hline 8 & M & 35 & ” & ” & Unknown & Complete & 3 months & 14 & Reiter's disease \\
\hline 9 & M & 19 & , & ” & Partial & Partial & Immediate & 4 & ? Ankylosing spondylitis \\
\hline 10 & $M$ & 21 & , & ", & Complete & Complete & Immediate & 3 & Iritis; HLA-B27 antigen \\
\hline 11 & $\stackrel{M}{M}$ & 33 & 二 & " & 二 & Complete & 2 months & 16 & Psoriasis; urethritis; HLA-B27 antigen \\
\hline $\begin{array}{l}12 \\
13\end{array}$ & $\stackrel{\mathrm{F}}{\mathrm{M}}$ & $\begin{array}{l}53 \\
55\end{array}$ & Calcaneum & ”, & Complete & $\begin{array}{l}\text { None } \\
\text { Complete }\end{array}$ & Immediate & $\begin{array}{l}2 \\
3\end{array}$ & \\
\hline 14 & M & 30 & " & $\begin{array}{l}\text { Tendo } \\
\text { calcaneus }\end{array}$ & None & None & & Lost & HLA-B27 antigen \\
\hline 15 & M & 68 & $\begin{array}{l}\text { Tendo } \\
\text { calcaneus }\end{array}$ & - & ", & 一 & & 21 & Responded to ultrasound; spontaneous rupture left tendo calcaneus \\
\hline $\begin{array}{l}16 \\
17\end{array}$ & $\begin{array}{l}M \\
M\end{array}$ & $\begin{array}{l}63 \\
48\end{array}$ & $\begin{array}{c}\text { calcaneus } \\
\text { ” }\end{array}$ & $\underset{\text { Tendo }}{\text { calcaneus }}$ & Complete & Complete & Immediate & $\begin{array}{r}8 \\
25\end{array}$ & Reiter's disease; HLA-B27 antigen \\
\hline
\end{tabular}

